\title{
Laparoscopically assisted Adenomyomectomy Using the Double| Multiple-Flap Method with Temporary Occlusion of the Bilateral Uterine Artery and Utero-Ovarian Vessels in Comparison with the Double/Multiple-Flap Only Method
}

\author{
Vergleich der laparoskopisch assistierten Adenomyomektomie unter \\ Verwendung der Doppel-|Mehrfach-Lappen-Methode mit vorüber- \\ gehender Okklusion der bilateralen Arteria uterina und der utero- \\ ovariellen Gefäße mit der Doppel-|Mehrfach-Lappen-Methode alleine
}

\section{(c) (9) $\Theta$}

Authors

Limei Ji*, Lanying Jin*, Shunjie Zheng, Mingjun Shao, Dawei Cui, Min Hu

Affiliation

Department of Obstetrics and Gynecology, Jinhua Municipal Central Hospital, Jinhua, China

Key words

adenomyomectomy, bilateral uterine artery, utero-ovarian vessels, double/multiple flap, temporary occlusion

Schlüsselwörter

Adenomyomektomie, bilaterale Arteria uterina, uteroovarielle Gefäße, Doppel-/Mehrfach-Lappen, vorübergehende Okklusion

received

19.6. 2020

accepted after revision

12. 12.2020

Bibliography

Geburtsh Frauenheilk 2021; 81: 321-330

DOI 10.1055/a-1337-2690

ISSN 0016-5751

(C) 2021. The Author(s).

This is an open access article published by Thieme under the terms of the Creative Commons Attribution-NonDerivative-NonCommercial-License, permitting copying and reproduction so long as the original work is given appropriate credit. Contents may not be used for commercial purposes, or adapted, remixed, transformed or built upon. (https://creativecommons.org/licenses/by-nc-nd/4.0/)

Georg Thieme Verlag KG, Rüdigerstraße 14,

70469 Stuttgart, Germany

Correspondence

Min $\mathrm{Hu}, \mathrm{MD}$

Department of Obstetrics and Gynecology, Jinhua Municipal

Central Hospital

No. 351 Renmin Xi Road, Jinhua, Zhejiang, 321000, China

jlm1104@126.com

\section{ABSTRACT}

Introduction Adenomyomectomy is the most conservative surgical treatment for adenomyosis. However, the surgical efficacy of this treatment and the best approach to use are still debated. We aimed to evaluate the efficacy of laparoscopic adenomyomectomy using the double/multiple-flap method combined with temporary occlusion of the bilateral uterine artery and the utero-ovarian vessels to treat symptomatic adenomyosis.

Patients We recruited 155 patients with symptomatic adenomyosis and divided them into group $A(n=76)$ and group $B(n=79)$, with each group treated using a different surgical approach. All eligible women were informed of the potential complications, benefits, and alternatives of each approach before they were assigned into one of the two groups. In group A, we performed laparoscopic adenomyomectomy with the double/multiple-flap method while in group B, we performed a double/multiple-flap adenomyomectomy combined with temporary occlusion of the bilateral uterine artery and uteroovarian vessels. Over a 24-month follow-up period, we evaluated operating time, intraoperative blood loss, visual analog scale (VAS) scores, anti-Mullerian hormone levels, uterine volume, and relief of menorrhagia.

Results There were no significant differences between groups A and B with respect to VAS scores, relief of menorrhagia and uterine volume at 3 months, 6 months, 12 months and 24 months after surgery $(p>0.05)$. Both groups showed significant improvement of these parameters after surgery compared with preoperative values $(p<0.05)$. Blood loss in group $B$ was significantly lower than in group $A(p<0.001)$

* Contributed equally to this work. 
while there was no significant difference in operating times $(p>0.05)$. Levels of AMH did not differ significantly between the groups throughout the follow-up period $(p>0.05)$.

Conclusion Laparoscopic adenomyomectomy with temporary occlusion of the bilateral uterine artery and the uteroovarian vessels offers a feasible surgical option to treat symptomatic adenomyoma.

\section{ZUSAMMENFASSUNG}

Einleitung Die Adenomyomektomie stellt die konservativste aller chirurgischen Methoden zur Behandlung einer Adenomyose dar. Aber die chirurgische Effektivität dieses Verfahrens und die beste Herangehensweise werden immer noch debattiert. Ziel dieser Studie war es, die Effektivität einer laparoskopischen Adenomyomektomie unter Verwendung der Doppel-/Mehrfach-Lappen-Methode zusammen mit einer vorübergehenden Okklusion der bilateralen $A$. uterina und der uteroovariellen Gefäße bei der Behandlung einer symptomatischen Adenomyose zu prüfen.

Patientinnen Insgesamt wurden 155 Patientinnen mit symptomatischer Adenomyose in die Studie aufgenommen. Die Patientinnen wurden entweder in Gruppe $A(n=76)$ oder in Gruppe B $(n=79)$ eingeteilt. Die chirurgische Behandlung unterschied sich in beiden Gruppen. Alle geeigneten Patientinnen wurden über mögliche Komplikationen, Vorteile und Alternativen beider Herangehensweisen aufgeklärt, bevor sie in eine der beiden Gruppen eingeteilt wurden. Die in Gruppe A durchgeführte Operation bestand aus einer laparoskopischen
Adenomyomektomie unter Einsatz der Doppel-/MehrfachLappen-Methode. Dagegen wurde in Gruppe B eine Doppel-/ Mehrfach-Lappen-Adenomyomektomie zusammen mit einer vorübergehenden Okklusion der bilateralen A. uterina und der uteroovariellen Gefäße durchgeführt. Die Patientinnen wurden 24 Monate lang nachbeobachtet. Ausgewertet wurden die Operationsdauer, der intraoperative Blutverlust, etwaige Änderungen der visuellen Analogskalawerte, des AntiMüller-Hormon-Spiegels und des Gebärmuttervolumens sowie die Linderung der Menorrhagie.

Ergebnisse Es gab keine signifikanten Unterschiede zwischen Gruppe A und Gruppe B hinsichtlich der VAS-Werte, der Linderung der Menorrhagie und des Gebärmuttervolumens 3, 6, 12 und 24 Monate nach der Operation ( $p>0,05)$. Bei beiden Gruppen gab es eine signifikante Verbesserung dieser Parameter nach der Operation, verglichen mit den präoperativen Werten $(p<0,05)$. Der Blutverlust in Gruppe B war signifikant niedriger als der von Gruppe $A(p<0,001)$. Bei der Operationsdauer gab es keine signifikanten Unterschiede zwischen beiden Gruppen ( $p>0,05)$. Der AMH-Spiegel in der Nachbeobachtungzeit unterschied sich nicht signifikant zwischen beiden Gruppen ( $p>0,05$ ).

Schlussfolgerung Die laparoskopische Adenomyomektomie mit vorübergehender Okklusion der bilateralen A. uterina und der uteroovariellen Gefäße stellt eine praktikable chirurgische Option zur Behandlung der symptomatischen Adenomyose dar.

\section{Introduction}

Adenomyosis is a common gynecological tumor that is characterized by endometrial tissue and stroma invading the myometrium. Depending on the extent of the lesion, the disease is categorized either as localized or diffuse adenomyosis. The major clinical manifestations include severe dysmenorrhea, hypermenorrhea, chronic pelvic pain, and infertility [1]. This condition is usually complicated by endometrial cysts of the ovary, pelvic endometriosis, hysteromyoma, or other estrogen-dependent diseases. There is no consensus about the most appropriate method to treat symptomatic uterine adenomyosis in patients who desire to preserve their fertility. Medical treatment is often the first choice for adenomyosis and includes the administration of gonadotropin-releasing hormone $(\mathrm{G} n \mathrm{RH})$ agonists, oral contraceptives, progestins, aromatase inhibitors, and danazol [2]. However, the effect of these treatments is transient; following withdrawal of the medication, the lesions undergo rapid regrowth and there is a relapse in symptoms, particularly pain [3]. When medical treatment fails, complete hysterectomy is a definitive approach that can be used to treat symptomatic adenomyosis. However, total hysterectomy is inappropriate for women who wish to preserve their fertility and uterus. Many conservative surgical options have been developed to treat adenomyosis; adenomyomectomy is the most conservative surgical method that can be used to preserve fertility $[4,5]$. Excisional surgical techniques for adenomyosis include the transverse $\mathrm{H}$-incision technique and wedge-shaped excision of the uterine wall; however, these methods are frequently associated with spontaneous uterine rupture during a subsequent pregnancy, as well as the recurrence of adenomyosis [5]. In a previous study, Hisao et al. [1] reported a novel laparoscopic protocol for adenomyomectomy which incorporated a triple-flap method; this method was shown to achieve good results. Subsequently, Grimbizis et al. [6] showed that the therapeutic effect of a double-flap method was significantly better than conventional surgery, and that the clinical effect was the same as that of the triple-flap method. However, the triple-flap method for laparoscopic adenomyomectomy is limited by heavy bleeding. For this form of surgery to be carried out safely, it is important that the operative field is clean and stable. Kwon et al. [7] introduced a laparoscopic technique for adenomyomectomy that was carried out under transient occlusion of the uterine arteries (TOUA). In the current study, we report on an operative procedure, based on the pioneering work of Kwon et al., consisting of a laparoscopic-assisted adenomyomectomy using the double/multiple-flap method combined with temporary occlusion of the bilateral uterine artery and utero-ovarian vessels to treat uterine adenomyosis. 


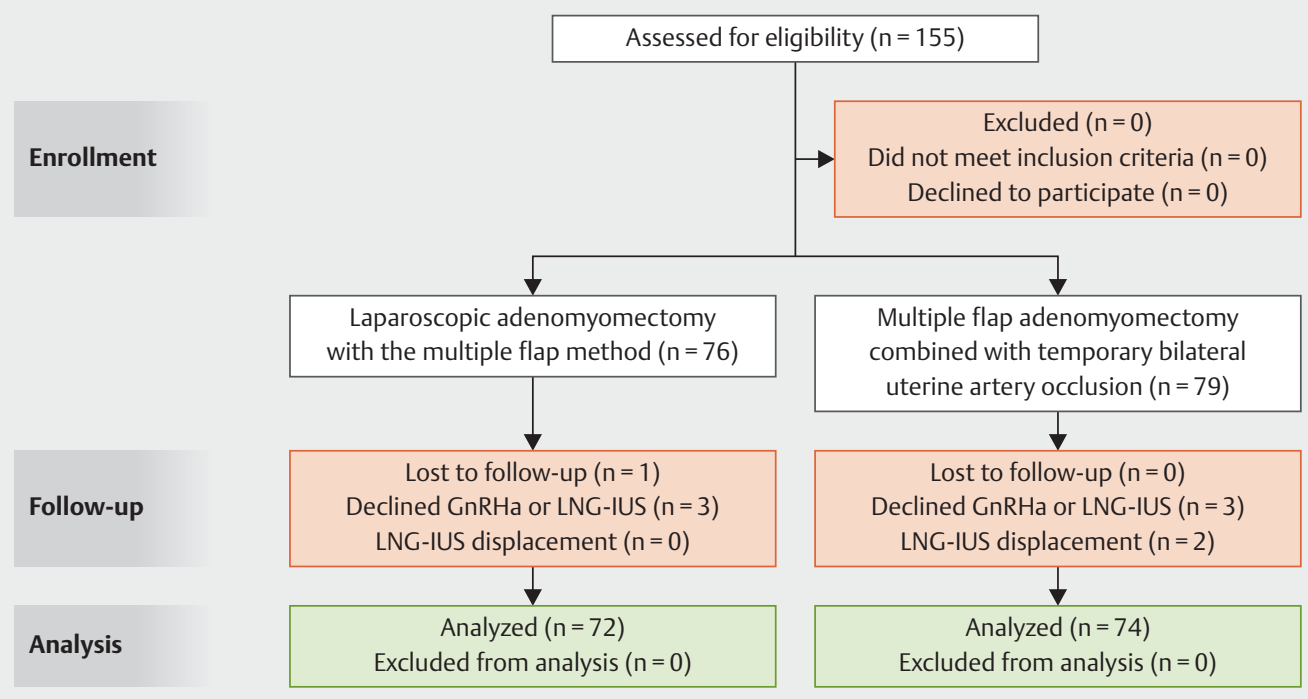

- Fig. 1 CONSORT flow diagram.

\section{Material and Methods}

\section{Patient selection}

This single-center study involved a retrospective analysis of symptomatic patients with adenomyosis who were treated at the jinhua Municipal Central Hospital from May 2014 to January 2017. Group A consisted of 76 patients and Group B consisted of 79 patients ( $\triangleright$ Fig. 1). All patients provided written informed consent before recruitment. All eligible women were informed of the potential complications, benefits, and alternatives of each approach before they were assigned into one of the two groups. This research was approved by the Ethics Committee of Jinhua Municipal Central Hospital. Adenomyosis can be classified into four subtypes based on magnetic resonance imaging (MRI) geography [8]. Subtype I (intrinsic) adenomyosis resides in the inner layer of the uterus without disrupting the other components. Subtype II (extrinsic) adenomyosis occurs in the outer layer of the uterus without affecting the inner structures. Subtype III (intramural) adenomyosis occurs only in the myometrium. Adenomyosis that does not satisfy the above criteria is known as subtype IV; this subtype does not have a specific definition and represents a mixture of advanced cases from subtypes I-III. All patients were required to undergo a preoperative diagnostic examination to rule out other comorbidities.

The inclusion criteria were as follows:

1. women with subtype II, III and IV adenomyosis;

2. women experiencing severe dysmenorrhea (VAS $\geq 7$ ) with or without hypermenorrhea, and in whom drug treatment had failed, including oral contraceptives, GnRHa, progestins, and aromatase inhibitors;

3. women who wished to preserve their uterus, although their fertility was not an essential requirement;
4. women in whom adenomyosis had been verified preoperatively by ultrasound (which helped to eliminate other conditions with similar symptoms) and pelvic magnetic resonance imaging (MRI) had been carried out to identify the exact location and size of the lesion and its relationship with the uterine cavity according to specific diagnostic criteria; and

5. women with symptomatic adenomyosis measuring $30 \mathrm{~mm}$ or greater in focal adenomyosis and affecting more than $70 \%$ of the anterior and/or posterior myometrium with an enlargement of more than $5 \mathrm{~cm}$ in thickness in diffuse adenomyosis.

The MRI films of 8 of the 146 patients ( 3 patients in group A and 5 patients in group B) were not available in our hospital because imaging had been performed in other institutions.

The exclusion criteria included the coexistence of pelvic disease, such as extensive endometriosis, pelvic inflammatory disease, or genital malignant tumor. We also excluded patients whose postoperative pathological findings for adenomyoma were negative.

All patients were informed about the potential risks of hysterectomy or laparotomy. The operating time was measured from the first skin incision to closure. The size of the adenomyosis was defined as the maximum diameter of the adenomyosis, as determined by MRI. Operative blood loss was estimated by gathering the blood volume in suction bottles during surgery.

\section{Surgical technique}

All of the cases recruited in this study were operated on by five experienced gynecologists ("Associate Senior" or above). The patients were placed in the Trendelenburg position at 30 degrees. After general anesthesia, we performed the laparoscopic procedure with 4 trocars. In all cases, diluted vasopressin was injected into the myometrium at the beginning of surgery. 

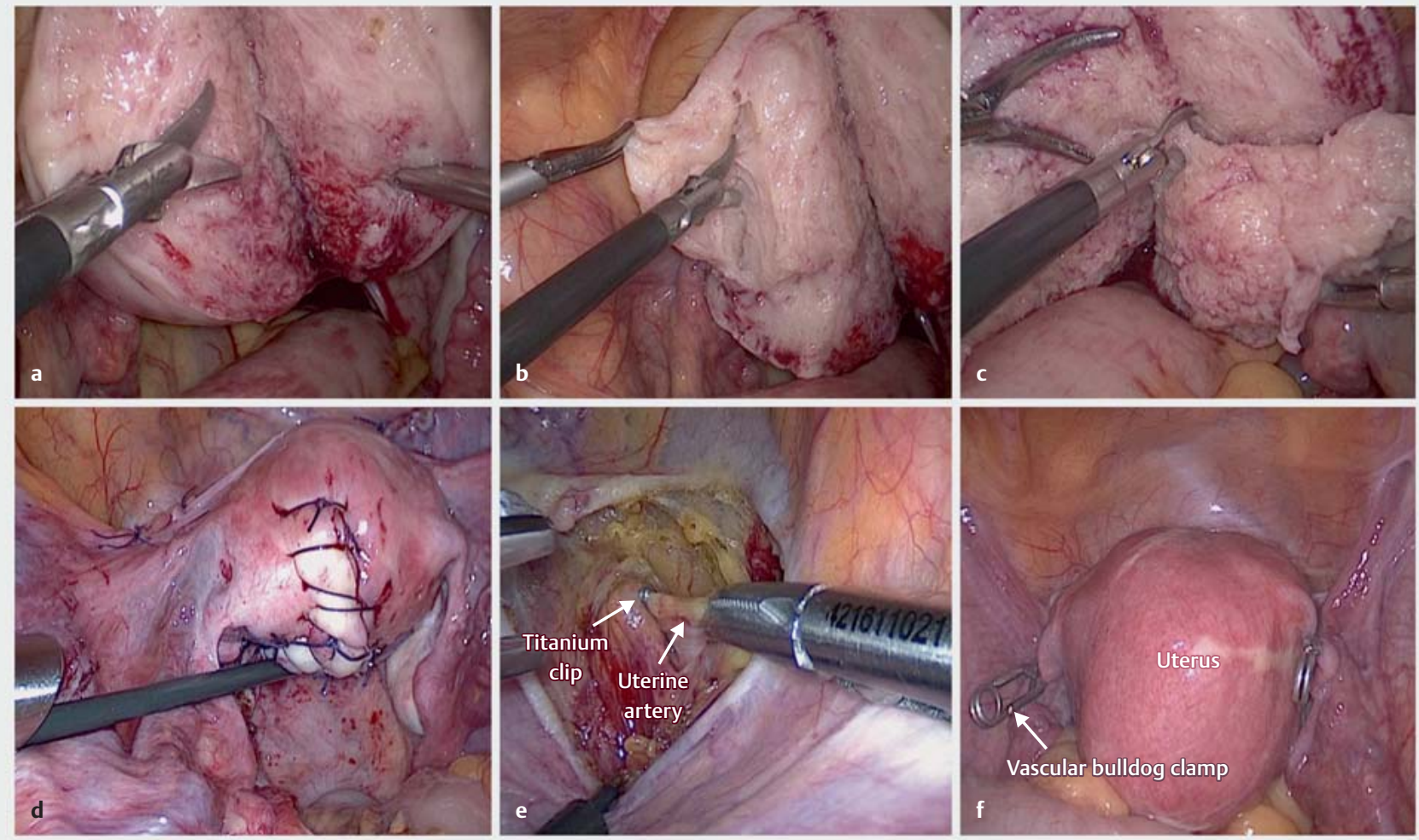

- Fig. 2 a The adenomyotic tissue is split into two or more parts. b and c The adenomyotic tissue is excised with endoscopic scissors. $\mathbf{d}$ The reconstruction process between the flaps. e A titanium clip on the left side of uterine artery. $f$ Transient occlusion of utero-ovarian vessels with a vascular bulldog clamp.

In group $\mathrm{A}$, the uterine serosa covering the adenomyotic tissue was incised using a monopolar cutting electrode until the endometrium or the interior of the uterine cavity was visually exposed. Because we needed a sufficient depth of incision, the adenomyotic tissue was split into two or more parts ( $\bullet$ Fig. 2 a). The adenomyotic tissue was then excised with endoscopic scissors ( $\triangleright$ Fig. $\mathbf{2 b}$ and $\mathbf{c}$ ). The surgeon differentiated adenomyotic tissue from normal muscle layer based on tactile and visual sensation for complete cytoreductive excision in cases with diffuse adenomyosis. In cases with localized adenomyosis, the focal lesions were completely removed. The involved endometrium was spared as much as possible, and the serosa covering the adenomyoma was retained at a depth of $5 \mathrm{~mm}$ to help with subsequent triple or double/multiple-flap reconstruction of excisional defects.

The defect area was closed using a specific suturing pattern. First, we sutured the endometrium; then we sutured one side of the multi-sectioned myometrium and the serosal flap to the endometrial side of the uterus with many deep and single interrupted sutures. During the reconstruction process, sutures were placed meticulously in order to avoid the development of hematoma between the flaps. Next, the serosal surface of the previously covered flap was removed to ensure that the tissue between the flaps was strongly attached. Finally, the other side of the flap was used to cover and suture the previous flap ( $>$ Fig. 2 d). The reconstruction process should be carried out in such a way that all sides of the uterus are evenly reconstructed without weak or thin areas. The external serous flap was sutured using the "baseball" method, so that the cutting edges could be inverted inside to reduce adhesion of the incision to the intestines, omentum, and peritoneum.

In group B, the anterior leaf of the broad ligament was separated by blunt and sharp dissection. We located the uterine artery via the posterior leaf of the broad ligament between the mesosalpinx and the round ligament. Application and removal of the titanium clip and clamp was performed according to the approach described in our previous paper ( $\bullet$ Fig. $2 \mathbf{e}$ and $\mathbf{f}$ ) [9]. Compared with other instruments, the clamp and titanium clip are easy to apply and remove and seem to cause less damage to the vessels involved. The remainder of the procedure was then carried out as described for group A. Finally, the titanium clips and the clamps were safely removed to allow the vessels to re-perfuse, and the peritoneum was closed with absorbable sutures. All specimens were confirmed by histopathological examination and malignancy was excluded postoperatively.

\section{Post-surgical follow-up and treatment}

After obtaining a pathological diagnosis, we treated all patients with six postoperative cycles of $\mathrm{GnRH}$ agonists (Ipsen Pharma Biotech, France). The first dose was given to all patients at the beginning of the first menstrual cycle after surgery, and use of the levo- 
norgestrel-releasing intrauterine system (LNG-IUS, Mirena, Bayer, Germany) was suggested after the completion of GnRHa treatment.

For a total of 2 years after surgery, we assessed improvements in symptoms, carried out ultrasound examinations and monitored anti-Mullerian hormone (AMH) levels as an indicator of fertility. The severity of pelvic pain was recorded using a standardized questionnaire with a visual analog scale (VAS) score ranging from 0 (no pain) to 10 (excruciating pain) [7]. All patients were asked to judge the amount of postoperative menstrual fluid discharge against the pre-surgery amount (classified as a 10) [10]; this was a relatively accurate method to compare postoperative with preoperative levels. changes in symptoms before and after surgery were compared.

Uterine volume was measured by ultrasonography (Volume $=$ $A \times B \times C \times 0.5233$ [in which $A, B$, and $C$ are the longitudinal dimension, anteroposterior dimension, and transverse dimension of the uterus, respectively]). Ultrasonography was performed by the same physician, who was not involved in this investigation and was also blinded to the ultrasonography findings before and after surgery. The maximum diameter of the lesion was used for analysis. MRI was not routinely evaluated after surgery due to excessive costs.

\section{Evaluation of therapeutic efficacy}

Therapeutic efficacy was graded according to the following criteria:

1. complete remission, in which dysmenorrhea completely disappeared after surgery;

2. significant remission, in which dysmenorrhea did not disappear completely and the VAS score was reduced by more than 3 grades;

3. partial remission, in which the VAS score was reduced by less than 2 grades, and dysmenorrhea did not disappear;

4. no remission, in which the VAS score did not change compared with preoperative levels; and

5. recurrence, in which complete or significant remission was achieved, but dysmenorrhea recurred and progressively increased 1 year after surgery, and the appearance of adenomyotic lesions was confirmed by ultrasound or MRI.

Complete remission and significant remission were defined as clinically effective treatment.

\section{Statistical Analysis}

SPSS version 17.0 (SPSS, Inc., IBM, Chicago, IL) was used to perform all statistical analyses. Data are presented as mean \pm standard deviation (SD), median (range), or absolute numbers (\%). The difference in means between the two groups was tested by analysis of variance (ANOVA). All p-values were two-tailed, and a $\mathrm{p}$-value $<0.05$ was considered statistically significant.

\section{Results}

\section{Patient characteristics}

None of the patients required conversion to laparotomy, and none suffered from major intraoperative or postoperative complications. Six patients (three in group A and three in group B) refused to take GnRHa or LNG-IUS treatment because they experienced complete remission of dysmenorrhea. One patient in group $A$ was lost to follow-up and 2 patients in group B were given LNG-IUS 4 months after implantation. After surgery, 42 patients (19 patients in group A and 23 patients in group B) had ovarian endometriosis confirmed by laparoscopy and postoperative pathology. Of the 42 patients, deep infiltrating endometriosis (DIE) was found during surgery in 19 women (9 patients in group A and 10 patients in group B) ( $\triangleright$ Table 1 ). The extent of DIE was determined intraoperatively using the revised ENZIAN and AFS score

- Table 1 Patient characteristics. The distribution of the enrolled patients' age, body mass index, operative time, and mean blood loss, and the subtypes and weight of the adenomyosis are described in detail. There was no difference in age, body mass index, operating time, weight of adenomyotic tissue and patients' adenomyosis subtypes between groups. The mean blood loss in group B was significantly lower than in group A $(p<0.001)$.

\begin{tabular}{|c|c|c|c|}
\hline Characteristics & $\begin{array}{l}\text { Group A } \\
(n=72)\end{array}$ & $\begin{array}{l}\text { Group B } \\
(n=74)\end{array}$ & p value \\
\hline Age (year) & $35.15 \pm 6.41$ & $34.05 \pm 5.73$ & 0.277 \\
\hline $\begin{array}{l}\text { Body mass index } \\
\left(\mathrm{kg} / \mathrm{m}^{2}\right)\end{array}$ & $20.06 \pm 1.42$ & $20.47 \pm 2.32$ & 0.190 \\
\hline $\begin{array}{l}\text { Operating time } \\
\text { (minutes) }\end{array}$ & $153.35 \pm 34.27$ & $161.69 \pm 42.99$ & 0.198 \\
\hline Blood loss (ml) & $344.26 \pm 95.52$ & $112.38 \pm 42.25$ & $<0.001$ \\
\hline $\begin{array}{l}\text { Weight of } \\
\text { adenomyotic } \\
\text { tissue (g) }\end{array}$ & $77.54 \pm 73.72$ & $86.55 \pm 46.38$ & 0.229 \\
\hline \multicolumn{4}{|l|}{$\begin{array}{l}\text { Adenomyosis } \\
\text { subtypes }\end{array}$} \\
\hline - subtype II & 36 & 39 & 0.890 \\
\hline - subtype III & 17 & 18 & \\
\hline - subtype IV & 19 & 17 & \\
\hline \multicolumn{4}{|l|}{ AFS stage } \\
\hline - stage I & 0 & 0 & 0.939 \\
\hline - stage II & 6 & 7 & \\
\hline - stage III & 9 & 12 & \\
\hline - stage IV & 4 & 4 & \\
\hline \multicolumn{4}{|l|}{$\begin{array}{l}\text { Coexisting } \\
\text { endometriosis }\end{array}$} \\
\hline $\begin{array}{l}\text { Ovarian } \\
\text { endometriosis }\end{array}$ & 19 & 23 & 0.531 \\
\hline $\begin{array}{l}\text { Deep infiltrating } \\
\text { endometriosis }\end{array}$ & 9 & 10 & 0.856 \\
\hline
\end{tabular}


[11] ( $\triangleright$ Tables 1 and 2 ) The remaining patients (72 in group A and 74 in group B) were all treated with GnRHa and LNG-IUS during the follow-up period. There were no statistical differences in terms of body mass index (BMI), age, uterine volume, VAS score and menorrhagia, when the two groups were compared preoperatively $(p>0.05)(\triangleright$ Table 1$)$.

\section{Comparison of mean blood loss, operating time and the weight of excised tissue between the two groups}

In group $B$, the mean blood loss was $112.38 \pm 42.25 \mathrm{ml}$; this was significantly lower than that in group A $(344.26 \pm 95.52 \mathrm{ml}$; $p<0.001)$. When the two groups were compared, there were no statistical differences in terms of adenomyosis subtypes, operating times, or the weight of the excised tissues $(p>0.05)(\triangleright$ Table 1).

\section{Comparison of VAS scores between the two groups}

At the 24-month follow-up point, the VAS scores in both groups were significantly lower than their preoperative scores $(p<0.001)$. Compared with the preoperative status, the VAS score at the first menstrual cycle after surgery was statistically lower in both groups $(p<0.001)$. At the first follow-up after the first postoperative menstruation, it was evident that in both groups, VAS scores had improved significantly after medical treatment $(p<0.001)$. The VAS scores were similar in both groups when compared at 6 and 12 months after surgery and at 12 and 24 months after surgery $(p>0.05)$ and there were no significant differences between the two groups in the following period $(p>0.05)$; the scores for each group were significantly lower than those recorded before surgery $(p<0.001)(>$ Table 3$)$. The effective rate of dysmenorrhea remission decreased gradually over time in the 6 months after surgery, and the differences with respect to the effective rate between the two groups at each timepoint after surgery did not reach statistical significance $(p>0.05)$ $(\triangleright$ Table 4). However, 24 months after surgery, one patient $(1 / 72$, $1.35 \%$ ) in group A showed dysmenorrhea; the VAS score of this patient was 6.5.

\section{Comparison of uterine size, $\mathrm{AMH}$, and menstrual blood flow between the two groups}

After surgery, uterine sizes did not differ significantly between the two groups ( $p>0.05$ ), and mean size (in both groups) was significantly lower than preoperative values $(p<0.001)$ ( $\triangleright$ Table 3 ). $\mathrm{AMH}$ levels did not differ significantly between the two groups at first menstruation, 12 months, and 24 months postoperatively. The AMH levels in both groups showed a small but significant decrease at the time of the first postoperative menstruation $(\mathrm{p}<0.05)(\triangleright$ Table 3$)$.

There was no significant difference in menstrual blood flow between the two groups during the first menstrual cycle after surgery, or at 12 and 24 months after surgery $(p>0.05)$. The menstrual volume in each group was significantly lower compared to preoperative volumes $(p<0.001)(\triangleright$ Table 3$)$. In group A, all cases experienced normal menstruation after surgery. However, one patient in group B suffered from menorrhagia at 24 months after surgery; the menstrual volume was 5.5. In both groups, menstrual
- Table 2 Histopathological ENZIAN staging for all observed DIE lesions.

\begin{tabular}{|c|c|c|}
\hline Lesions & $\begin{array}{l}\text { Group A } \\
(n=76)\end{array}$ & $\begin{array}{l}\text { Group B } \\
(n=79)\end{array}$ \\
\hline $1 \mathrm{~A}$ & 3 & 2 \\
\hline $2 \mathrm{~A}$ & 2 & 1 \\
\hline $3 \mathrm{~A}$ & 1 & 1 \\
\hline 1B & 4 & 5 \\
\hline 2B & 1 & 2 \\
\hline 3B & 0 & 1 \\
\hline $1 C$ & 1 & 2 \\
\hline $2 C$ & 2 & 1 \\
\hline $3 C$ & 1 & 0 \\
\hline FA & 76 & 79 \\
\hline FB & 1 & 0 \\
\hline FU & 0 & 2 \\
\hline $\mathrm{Fl}$ & 0 & 0 \\
\hline FO & 0 & 0 \\
\hline \multicolumn{3}{|c|}{ A = vaginal/rectovaginal endometriosis } \\
\hline \multicolumn{3}{|c|}{$\mathrm{B}=$ endometriosis of the uterosacral ligaments } \\
\hline \multicolumn{3}{|c|}{$\mathrm{C}=$ rectosigmoid endometriosis } \\
\hline \multicolumn{3}{|c|}{$\mathrm{FA}=$ adenomyosis } \\
\hline \multicolumn{3}{|c|}{$\mathrm{FB}=$ bladder endometriosis } \\
\hline \multicolumn{3}{|c|}{$\mathrm{FU}=$ ureteral endometriosis } \\
\hline \multicolumn{3}{|c|}{$\mathrm{FI}=$ endometriosis of the sigma, cecum and ileum } \\
\hline \multicolumn{3}{|c|}{$\begin{array}{l}\text { FO = other types of endometriosis } \\
\text { (such as diaphragm, liver, abdominal wall, etc.) }\end{array}$} \\
\hline
\end{tabular}

flow at 24 months after surgery did not differ significantly compared with that at 12 months after surgery $(p>0.05)$.

Two cases experienced menorrhagia and dysmenorrhea after surgery. One patient in group A suffered from dysmenorrhea (VAS $=6.5$ ) and required a second round of surgery. In the process of carrying out hysteroscopic endometriosis surgery as a definitive treatment 28 months after surgery, we found multiple cystic adenomyoma lesions in the myometrium. The other patient who suffered from dysmenorrhea is still being followed up.

\section{Discussion}

Adenomyosis is the most frequently identified gynecological tumor in women in their late reproductive years [12]. In severe cases, this condition not only influences physical health, it can also affect mental health and have a negative impact on quality of life. Generally, women wish to preserve their uterus, particularly in the Chinese population. This is for cultural and emotional reasons and because they may wish to become pregnant in the future. In patients with diffuse adenomyosis, laparotomic adenomyomectomy has recently been considered to be the ideal choice for the radical resection of adenomyotic tissue to relieve adenomyoma-related symptoms and preserve fertility [5]. As our clinical experience has grown and minimally invasive techniques have become in- 
- Table 3 Therapeutic outcomes during follow-up. In the period after surgery, VAS scores, menstrual blood flow, menstrual volume, the uterine size and serum AMH levels were recorded. The VAS scores in both groups decreased significantly compared with those before surgery ( $p<0.001)$; the VAS scores were similar at 6 and 12 months after surgery and at 12 and 24 months after surgery in both groups $(p>0.05)$ and there were no significant differences between the two groups $(p>0.05)$. Menstrual blood flow was not significantly different between the two groups during menstruation at 12 and 24 months after surgery $(p>0.05)$, and menstrual volume in each group was significantly lower compared to the volumes prior to surgery $(p<0.001)$. Uterine size and serum AMH levels did not differ significantly between the two groups $(p>0.05)$, and both parameters in each group had decreased significantly compared with those obtained prior to surgery $(p<0.001)$.

\begin{tabular}{|c|c|c|c|c|}
\hline & VAS & Menorrhagia & $\begin{array}{l}\text { Estimated uterine } \\
\text { volume, } \mathrm{cm}^{3}\end{array}$ & AMH, $\mathrm{ng} / \mathrm{ml}$ \\
\hline \multicolumn{5}{|l|}{ Baseline } \\
\hline - Group A & $8.22 \pm 0.81$ & 10 & $228.33 \pm 36.63$ & $4.47 \pm 2.26$ \\
\hline - Group B & $8.35 \pm 0.82$ & 10 & $218.70 \pm 38.59$ & $5.08 \pm 1.40$ \\
\hline - pvalue & 0.355 & - & 0.124 & 0.057 \\
\hline \multicolumn{5}{|c|}{ At the first postoperative menstruation } \\
\hline - Group A & $2.48 \pm 1.49$ & $4.23 \pm 1.84$ & - & $3.64 \pm 1.92$ \\
\hline - Group B & $2.91 \pm 1.54$ & $3.87 \pm 2.13$ & - & $3.81 \pm 1.89$ \\
\hline - pvalue & 0.085 & 0.272 & - & 0.594 \\
\hline \multicolumn{5}{|l|}{3 months } \\
\hline - Group A & - & - & $72.76 \pm 10.98$ & - \\
\hline - Group B & - & - & $69.85 \pm 10.02$ & - \\
\hline " pvalue & - & - & 0.096 & - \\
\hline \multicolumn{5}{|l|}{6 months } \\
\hline - Group A & $0.29 \pm 0.71$ & - & $69.92 \pm 12.09$ & - \\
\hline - Group B & $0.31 \pm 084$ & - & $67.95 \pm 13.01$ & - \\
\hline - pvalue & 0.891 & - & 0.345 & - \\
\hline \multicolumn{5}{|l|}{12 months } \\
\hline - Group A & $0.39 \pm 0.93$ & $1.24 \pm 0.64$ & $70.07 \pm 11.12$ & $4.28 \pm 2.02$ \\
\hline - Group B & $0.36 \pm 0.81$ & $1.32 \pm 0.76$ & $66.55 \pm 11.19$ & $4.77 \pm 1.80$ \\
\hline - pvalue & 0.831 & 0.487 & 0.059 & 0.122 \\
\hline \multicolumn{5}{|l|}{24 months } \\
\hline - Group A & $0.40 \pm 1.04$ & $1.37 \pm 0.68$ & $72.56 \pm 13.37$ & $4.03 \pm 2.04$ \\
\hline - Group B & $0.31 \pm 0.70$ & $1.41 \pm 0.81$ & $70.30 \pm 10.03$ & $4.61 \pm 2.07$ \\
\hline - pvalue & 0.530 & 0.723 & 0.249 & 0.091 \\
\hline
\end{tabular}

creasingly popular, we have been able to address the difficulties associated with laparoscopic adenomyomectomy, at least to a certain extent. We suggest that a laparoscopic approach is an appropriate treatment to treat uterine adenomyosis. Conventional partial adenomyomectomy procedures such as the transverse $\mathrm{H}$ incision technique and wedge-shaped excision of the uterine wall have also been reported [5]. Excision results in the incomplete removal of adenomyotic tissue and may create difficulties when attempting functional reconstruction of the remaining myometrium; this is due to the extensive loss of the muscle layer [5]. In adenomyosis, the endometrial tissue penetrates the myometrium; the boundary between the adjacent normal layer and the adenomyotic tissue thus becomes unclear. This causes difficulties during dissection and can result in heavy intraoperative bleeding. The operating time is usually longer for laparoscopic excision of adenomyosis than for laparoscopic myomectomy, and operating times depend very much on difficulties encountered during the suturing process and levels of intraoperative bleeding. Therefore, controlling bleeding is an important factor. Efforts to control intraoperative bleeding have were introduced by Morita et al. [13] who administrated local vasopressin, Osada et al. [10] who reported the use of a supracervical tourniquet, and Kwon et al. [7] who used a clip to transiently occlude the uterine arteries during laparotomy. Maintaining a stable condition and limiting the amount of bleeding is very important if we are to complete laparoscopic adenomyomectomy procedures safely and relatively simply. In the present investigation, we based our concept on pioneering work and carried out laparoscopic adenomyomectomy using the double/multiple-flap method combined with temporary occlusion of the bilateral uterine artery and utero-ovarian vessels to excise the adenomyotic tissue. 
- Table 4 Dysmenorrhea relief and adenomyosis recurrence after adenomyomectomy. Rates of dysmenorrhea remission were recorded in the period after surgery. The effective rate of dysmenorrhea remission decreased over time 6 months after surgery, and the differences in the effective rate between the two groups at each time-point after surgery did not reach statistical significance $(p>0.05)$.

\begin{tabular}{|c|c|c|c|c|c|}
\hline & \multicolumn{4}{|c|}{ Dysmenorrhea remission (\%) } & \multirow[t]{2}{*}{ Effective } \\
\hline & $\begin{array}{l}\text { Complete } \\
\text { remission }\end{array}$ & $\begin{array}{l}\text { Significant } \\
\text { remission }\end{array}$ & $\begin{array}{l}\text { Partial } \\
\text { remission }\end{array}$ & No remission & \\
\hline \multicolumn{6}{|l|}{ Group A } \\
\hline $\begin{array}{l}\text { At the first postoperative } \\
\text { menstruation }\end{array}$ & $48.61(35 / 72)$ & $13.89(10 / 72)$ & $30.56(22 / 72)$ & $6.94(5 / 72)$ & $62.5(45 / 72)$ \\
\hline 6 months & $93.06(67 / 72)$ & $6.97(5 / 72)$ & 0 & 0 & $100(72 / 72)$ \\
\hline 12 months & $84.72(61 / 72)$ & $12.5(9 / 72)$ & $2.78(2 / 72)$ & 0 & $97.22(70 / 72)$ \\
\hline 24 months & $80.55(58 / 72)$ & $15.28(11 / 72)$ & $2.78(2 / 72)$ & $1.39(1 / 72)$ & $95.83(69 / 72)$ \\
\hline \multicolumn{6}{|l|}{ Group B } \\
\hline $\begin{array}{l}\text { At the first postoperative } \\
\text { menstruation }\end{array}$ & $50(36 / 74)$ & $13.51(10 / 74)$ & $32.43(24 / 74)$ & $5.41(4 / 74)$ & $62.16(46 / 74)$ \\
\hline 6 months & $91.89(68 / 74)$ & $8.11(6 / 74)$ & 0 & 0 & $100(74 / 74)$ \\
\hline 12 months & $85.14(63 / 74)$ & $13.51(10 / 74)$ & $1.35(1 / 74)$ & 0 & $96.65(73 / 74)$ \\
\hline 24 months & $78.38(58 / 74)$ & $18.92(14 / 74)$ & $2.70(2 / 74)$ & 0 & $97.30(72 / 74)$ \\
\hline
\end{tabular}

Our results show that all of our cases experienced significant remission in terms of uterine size, menorrhagia and pain symptoms after surgery. None of the patients developed endometriotic lesions in other areas during the follow-up period. Menorrhagia and dysmenorrhea are the characteristic symptoms of adenomyosis and are directly related to the therapeutic efficacy of adenomyomectomy [14-16]. An enlarged uterus is also a primary symptom of adenomyosis, and the reduction of uterine size is also correlated with surgical efficacy $[17,18]$. Long-term follow-up suggested that, compared to the preoperative state, both group $A$ and group $B$ achieved a reduction in uterine volumes $(p<0.001)$. It is clear that laparoscopic adenomyomectomy can be used to treat uterine adenomyosis effectively [5]. However, the efficacy of wedge resection for adenomyosis has been reported to be less than $65 \%$ [19]; furthermore, when postoperative follow-up was prolonged, menorrhagia and uterine size relapsed. We identified statistical differences in VAS scores and menstrual volume compared to preoperative parameters and at the first menstrual cycle after surgery $(p<0.001)$. At the first follow-up after the first postoperative menstruation, we found that VAS scores had significantly improved following medical treatment $(p<0.001)$. In a previous study, Wang et al. [20] reported that a combination of surgical and medical $(\mathrm{GnRHa})$ treatment provided more effective symptom control than surgery alone during the first two years after treatment. The effect of GnRH agonists is known to be transient [3]. In the present study, we introduced the use of LNG-IUS following the completion of GnRHa treatment. The LNG-IUD releases $20 \mathrm{mg}$ of levonorgestrel each day and represents an effective treatment for adenomyosis [21]. Zhu et al. [22] further reported that the recurrence rate was significantly higher in patients who were only treated with GnRHa after surgery than in patients who were treated with GnRHa plus LNG-IUS after surgery ( 51.6 vs. $8.3 \%$; $p<0.05)$. In our study, patients in both groups showed a lower rate of relapse $(n=1,1.39 \%$ vs. $n=1,1.35 \%)$ than previously reported $(n=32,28.1 \%)[20]$ at the end of the 2-year follow-up period. These results are consistent with those reported previously by Zhu et al. [22]. In our study, we found that the double/multiple-flap method could remove adenomyomatic lesions more radically and could reduce the risk of recurrence over time, at least theoretically. Another study has demonstrated that LNG-IUS may have a direct influence on the eutopic endometrium as the origin of the disease [23] and indicated that LNG-IUS can control symptoms and prevent recurrence after surgery. These previous findings are consistent with our present results in that we demonstrated a low rate of relapse for related symptoms and none of the patients developed adenomyotic lesions or ovarian endometriosis in the uterus or ovaries, as confirmed by ultrasound or MRI during follow-up.

The therapeutic efficacy of adenomyomectomy is mainly dependent on the extent and type of adenomyosis as well as the surgical technique used [5]. It is necessary to select the optimal treatment for the right patient. In cases involving focal adenomyosis (subtype III), the first-line approach is laparoscopic total lesion excision. In women with diffuse and mixed adenomyosis (subtypes II and IV), aggressive excision of the adenomyotic lesion may be the best course of treatment. The surgical techniques used for adenomyomectomy can be divided into two types, according to how much of the adjacent normal layer is removed and the extent to which the integrity and function of the uterus is preserved. Type I involves the total and complete eradication of adenomyosis while type II is a cytoreductive procedure [24]. In the present study, the method we adopted for subtype III was classified as type I while subtypes II and IV were classified as type II. We attempted to perform laparoscopic adenomyomectomy based on the technique described by Osada et al. [10] and Kim et al. [25]. During surgery, the bilateral uterine artery and utero- 
ovarian vessels were occluded to avoid excessive bleeding. In addition, the uterine cavity was opened entirely so that the full extent of the adenomyosis was visible, including the crucial landmarks of the endometrium and the serosal surface. This facilitated the excision of affected tissues more thoroughly than conventional surgery.

As follow-up time increased, almost all of the cases experienced normal menstruation. VAS scores and uterine volumes were similar during follow-up. These results indicate that laparoscopic adenomyomectomy using the double/multiple-flap method was more effective at treating uterine adenomyosis than conventional surgery; these findings concur with other previously reported findings $[5,24]$. However, two of our patients still experienced menorrhagia and dysmenorrhea after surgery. MRI revealed that one of these patients suffered from dysmenorrhea; this manifested in the form of multiple cystic adenomyoma lesions (1-10 mm in diameter) in the myometrium. Dysmenorrhea and other symptoms, including hypogastric pain and lumbago, can develop over time in cases with cystic adenomyoma [26].

Estimated blood loss was $112.38 \pm 42.25 \mathrm{ml}$ in group $\mathrm{B}$; this was significantly lower than that in the double/multiple-flap only group (344.26 $\pm 95.52 \mathrm{ml} ; \mathrm{p}<0.001)$. These findings concur with a previous report [1]. Morita et al. [13] administered vasopressin locally to control bleeding; however, the half-life of vasopressin is only 24.1 minutes [27] and the time taken to suppress bleeding from the incision was short compared with the duration of the procedure; furthermore, repeated doses of vasopressin can have an adverse effect on systemic circulation [28]. In our study, approximately 5 min was spent separating the uterine artery and occluding the transient uterine artery and utero-ovarian vessels in group B. This allowed us to successfully control intraoperative bleeding and did not lead to a significant increase in operating times ( $p=0.198)$. It is important to note that the clips applied to the uterine artery do not affect ovarian blood supply or function [9] and that the vascular clamps have a gap at the most proximal section of the device where there are no serrations. When applied to this area, the clamp does not damage the fallopian tubes or vessels [9]. In a previous study, Seifer et al. [29,30] showed that serum AMH levels may be the most reliable and easily measurable marker for ovarian reserve. According to the results of the present study, AMH levels showed a small but significant trend towards reduction (in both group $A$ and $B$ ) at the time of the first menstruation after surgery $(p<0.05)$; however, there was no significant difference between the two groups with regard to AMH levels thereafter $(p>0.05)$.

There are some limitations associated with our current research that should be taken into consideration. The follow-up period was short and the pregnancy rate was not considered because most patients in our study had completed childbearing and their fertility was not an essential requirement. The pregnancy rate needs to be investigated further in a randomized controlled study involving a larger number of cases.

Laparoscopic adenomyomectomy with temporary occlusion of the bilateral uterine artery and utero-ovarian vessels combined with the double/multiple-flap method is associated with significant advantages over the traditional form of double/multiple-flap surgery, including reduced blood loss and no increase in operating times.

\section{Disclosure Statement}

The authors report no conflicts of relevant financial, personal, political, intellectual or religious interests. The study was approved by the Ethics Committee of Jinhua Municipal Central Hospital (ethics approval number: 2017-52).

\section{Funding/Support Statement}

This research received no specific grant from any funding agency in the public, commercial, or not-for-profit sectors.

\section{Author Contributions}

$\mathrm{MH}$ conceived and designed this research study. DC, SZ, and MS acquired data. LJi, LJin and MS analyzed and interpreted the data. LJi drafted the manuscript and $\mathrm{MH}$ revised the manuscript.

\section{Acknowledgements}

Thanks are due to Lanying jin for valuable discussions.

\section{Conflict of Interest}

The authors declare that they have no conflict of interest.

\section{Reference}

[1] Osada H, Silber S, Kakinuma T et al. Surgical procedure to conserve the uterus for future pregnancy in patients suffering from massive adenomyosis. Reprod Biomed Online 2011; 22: 94-99

[2] Garcia L, Isaacson K. Adenomyosis: review of the literature. J Minim Invasive Gynecol 2011; 18: 428-437

[3] Chong GO, Lee YH, Hong DG et al. Long-Term Efficacy of Laparoscopic or Robotic Adenomyomectomy with or without Medical Treatment for Severely Symptomatic Adenomyosis. Gynecol Obstet Invest 2016; 81: 346-352

[4] Takeuchi H, Kitade M, Kikuchi I et al. Laparoscopic adenomyomectomy and hysteroplasty: A novel method. J Minim Invasive Gynecol 2006; 13: 150-154

[5] Huang X, Huang Q, Chen S et al. Efficacy of laparoscopic adenomyomectomy using double-flap method for diffuse uterine adenomyosis. BMC Womens Health 2015; 15: 24

[6] Grimbizis GF, Mikos T, Tarlatzis B. Uterus-sparing operative treatment for adenomyosis. Fertil Steril 2014; 101: 472-487

[7] Kwon YS, Roh H], Ahn JW et al. Laparoscopic adenomyomectomy under transient occlusion of uterine arteries with an endoscopic vascular clip. J Laparoendosc Adv Surg Tech A 2013; 23: 866-870

[8] Kishi $Y$, Suginami H, Kuramori R et al. Four subtypes of adenomyosis assessed by magnetic resonance imaging and their specification. Am J Obstet Gynecol 2012; 207: 114.e1-114.e7

[9] Jin I, Ji L, Shao M et al. Laparoscopic Myomectomy with Temporary Bilateral Uterine Artery and Utero-Ovarian Vessels Occlusion Compared with Traditional Surgery for Uterine Fibroids: Blood Loss and Recurrence. Gynecol Obstet Invest 2019; 84: 548-554 
[10] Osada H, Silber S, Kakinuma T et al. Surgical procedure to conserve the uterus for future pregnancy in patients suffering from massive adenomyosis. Reprod Biomed Online 2011; 22: 94-99

[11] Di Paola V, Manfredi R, Castelli F et al. Detection and localization of deep endometriosis by means of MRI and correlation with the ENZIAN score. Eur J Radiol 2015; 84: 568-574

[12] Garcia L, Isaacson K. Adenomyosis: review of the literature. J Minim Invasive Gynecol 2011; 18: 428-437

[13] Morita M, Asakawa Y, Nakakuma M et al. Laparoscopic excision of myometrial adenomyomas in patients with adenomyosis uteri and main symptoms of severe dysmenorrhea and hypermenorrhea. J Am Assoc Gynecol Laparosc 2004; 11: 86-89

[14] Huang BS, Seow KM, Tsui KH et al. Fertility outcome of infertile women with adenomyosis treated with the combination of a conservative microsurgical technique and GnRH agonist: long-term followup in a series of nine patients. Taiwan J Obstet Gynecol 2012; 51: 212-216

[15] Li X, Liu X, Guo SW. Clinical profiles of 710 premenopausal women with adenomyosis who underwent hysterectomy. J Obstet Gynaecol Res 2014; 40: 485-494

[16] Sheng J, Zhang WY, Zhang JP et al. The LNG-IUS study on adenomyosis: a 3-year follow-up study on the efficacy and side effects of the use of levonorgestrel intrauterine system for the treatment of dysmenorrhea associated withadenomyosis. Contraception 2009; 79: 189-193

[17] Kim ML, Seong SJ. Clinical applications of levonorgestrel-releasing intrauterine system to gynecologic diseases. Obstet Gynecol Sci 2013; 56: 67-75

[18] Zhang P, Song K, Li L et al. Efficacy of combined levonorgestrel-releasing intrauterine system with gonadotropin-releasing hormone analog for the treatment of adenomyosis. Med Princ Pract 2013; 22: 480-483

[19] Sun AJ, Luo M, Wang W et al. Characteristics and efficacy of modified adenomyomectomy in the treatment of uterine adenomyoma. Chin Med J (Engl) 2011; 124: 1322-1326
[20] Wang PH, Liu WM, Fuh JL et al. Comparison of surgery alone and combined surgical-medical treatment in the management of symptomatic uterine adenomyoma. Fertil Steril 2009; 92: 876-885

[21] Lydia G, Keith I. Adenomyosis: Review of the Literature. J Minim Invasive Gynecol 2011; 18: 428-437

[22] Zhu L, Chen S, Che X et al. Comparisons of the efficacy and recurrence of adenomyomectomy for severe uterine diffuse adenomyosis via laparotomy versus laparoscopy: a long-term result in a single institution. J Pain Res 2019; 12: 1917-1924

[23] Liu H, Lang JH. Is abnormal eutopic endometrium the cause of endometriosis? The role of eutopic endometrium in pathogenesis of endometriosis. Med Sci Monit 2011; 17: RA92-RA99

[24] Horng $\mathrm{HC}$, Chen $\mathrm{CH}$, Chen $\mathrm{CY}$ et al. Uterine-sparing surgery for adenomyosis and/or adenomyoma. Taiwan J Obstet Gynecol 2014; 53: 3-7

[25] Kim JK, Shin CS, Ko YB et al. Laparoscopic assisted adenomyomectomy using double flap method. Obstet Gynecol Sci 2014; 57: 128-135

[26] Takeuchi H, Kitade M, Kikuchi I et al. Diagnosis, laparoscopic management, and histopathologic findings of juvenile cystic adenomyoma: a review of nine cases. Fertil Steril 2010; 94: 862-868

[27] Shimanuki H, Takeuchi H, Kitade $M$ et al. The effect of vasopressin on local and general circulation during laparoscopic surgery. J Minim Invasive Gynecol 2006; 13: 190-194

[28] Riess ML, Ulrichs JG, Pagel PS et al. Case report: Severe vasospasm mimics hypotension after high-dose intrauterine vasopressin. Anesth Analg 2011; 113: 1103-1105

[29] Kwee J, Schats R, McDonnell J et al. Evaluation of anti-Müllerian hormone as a test for the prediction of ovarian reserve. Fertil Steril 2008; 90: 737743

[30] Seifer DB, Maclaughlin DT. Mullerian Inhibiting Substance is an ovarian growth factor of emerging clinical significance. Fertil Steril 2007; 88: 539-546 